\title{
EVALUATION OF CIRCULAR TEXTURE METER FOR MEASURING SURFACE TEXTURE OF PAVEMENTS
}

By

Douglas I. Hanson

Brian D. Prowell

September 2004

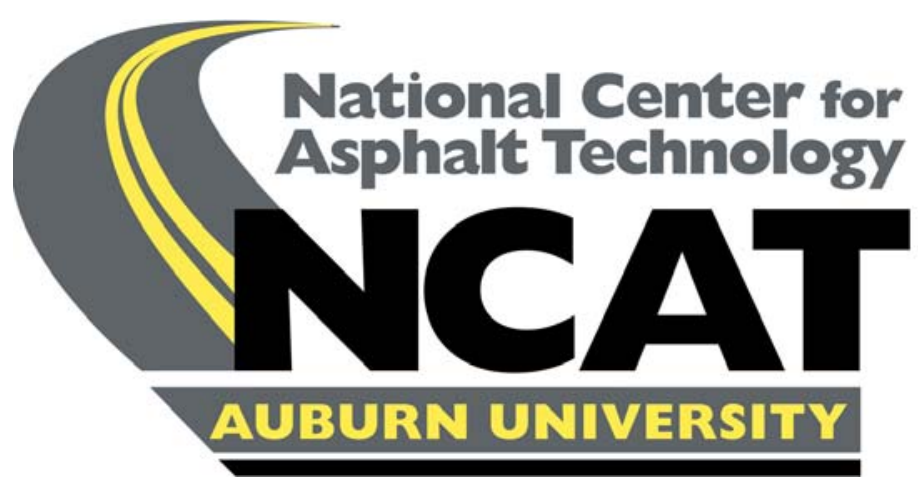

277 Technology Parkway Auburn, AL 36830 


\title{
EVALUATION OF CIRCULAR TEXTURE METER FOR MEASURING SURFACE TEXTURE OF PAVEMENTS
}

\author{
By: \\ Douglas I. Hanson \\ Assistant Director \\ National Center for Asphalt Technology \\ Auburn University, Auburn, Alabama \\ Brian D. Prowell \\ Assistant Director \\ National Center for Asphalt Technology \\ Auburn University, Auburn, Alabama
}

Sponsored by

Federal Highway Administration

NCAT Report 04-05

September 2004 


\section{DISCLAIMER}

The contents of this report reflect the views of the authors who are responsible for the facts and accuracy of the data presented herein. The material is based upon work supported by the Federal Highway Administration under Agreement No. DTFH610X0057. The contents do not necessarily reflect the official views or policies of the Federal Highway Administration or the National Center for Asphalt Technology. This report does not constitute a standard, specification or regulation. 


\section{TABLE OF CONTENTS}

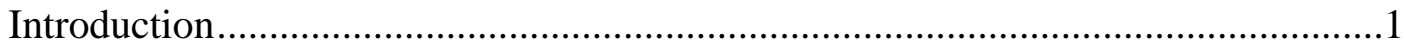

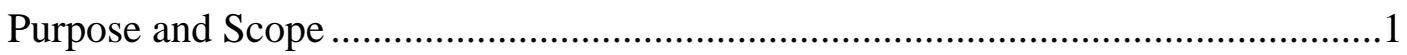

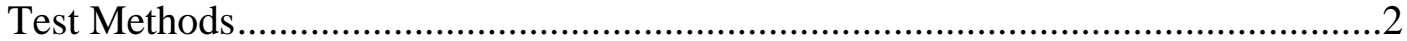

Circular Texture Meter ...........................................................................2

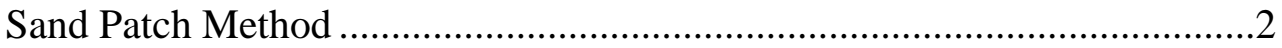

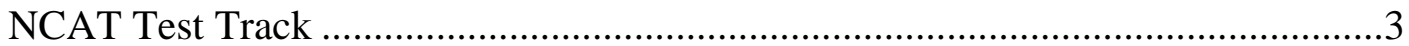

Results and Discussion ....................................................................................

Relationship between CT Meter and Sand Patch Test Results ......................3

Prediction of Mean Profile Depth .................................................................5

Variability of CT Meter Results .............................................................11

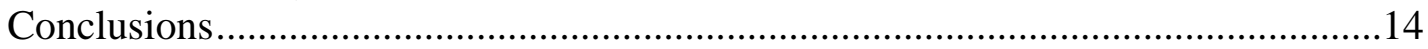

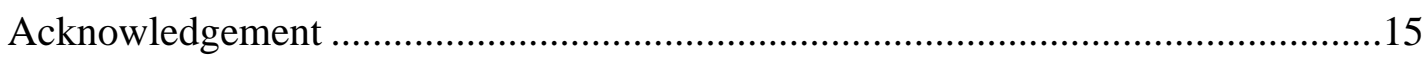

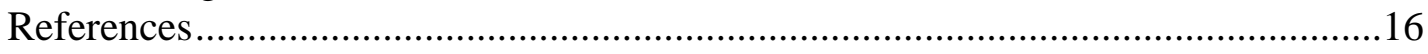

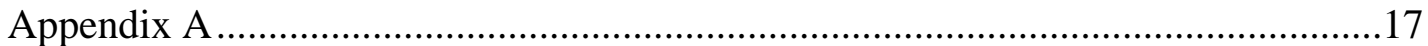

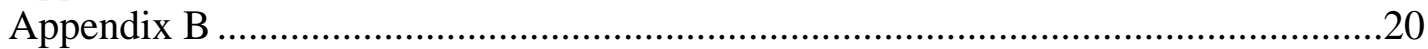




\begin{abstract}
The Circular Texture Meter (CT Meter) is a laser based device for measuring the mean profile depth (MPD) of a pavement at a static location. Both MPD measurements from the CT Meter and mean texture depth (MTD) measurements from the sand patch test were obtained in five random locations in each of 45 section of the 2000 National Center for Asphalt Technology (NCAT) Test Track. The NCAT Test Track provides a wide range of surface types including: coarse and fine dense graded Superpave mixes, Open Graded Friction Course (OGFC), Hveem mixes, Stone Mastic Asphalt (SMA) and Novachip. Testing indicated that CT Meter produced comparable results to the ASTM E965 Sand Patch Test. When open-graded mixtures were excluded, this study indicated that the offset was non-significant between CT Meter and sand patch test results.

Previously developed equations to predict macrotexture were found to be inadequate for the wide range of mix types and aggregate types found at the NCAT Test Track. An equation was developed to relate fineness modulus to macrotexture. This equation was validated with independent data collected by Virginia Transportation Research Council.

Testing conducted as part of a mini round robin indicated that two readings should be averaged to represent a single CT Meter measurement. The within-lab coefficient of variation for the CT Meter is estimated to be 2.3 percent. The between-lab coefficient of variation for the CT Meter is estimated to be 4.2 percent. Both estimates are based on the average of two tests being reported as a single measurement. This indicates that the CT Meter is more variable than the sand patch test. However, less technician skill is required to operate the CT Meter.
\end{abstract}




\title{
EVALUATION OF CIRCULAR TEXTURE METER FOR MEASURING SURFACE TEXTURE OF PAVEMENTS
}

\author{
Douglas I. Hanson and Brian D. Prowell
}

\section{INTRODUCTION}

Pavement friction during wet conditions continues to be a major safety concern for pavement design and maintenance. The friction of a pavement surface is a function of the surface textures that include the wavelength ranges described by microtexture, consisting of wavelengths of $1 \mu \mathrm{m}$ to $0.5 \mathrm{~mm}$, and macrotexture, with wavelengths of $0.5 \mathrm{~mm}$ to $50 \mathrm{~mm}$ (1). Microtexture provides a gritty surface to penetrate thin water films and produce good frictional resistance between the tire and the pavement. Macrotexture provides drainage channels for water expulsion between the tire and the pavement thus allowing better tire contact with the pavement to improve frictional resistance and prevent hydroplaning. Currently there is no system capable of measuring microtexture profiles at highway speeds. Therefore, microtexture is evaluated by using pavement friction at low speeds as a surrogate.

Pavement macrotexture, or more specifically changes in macrotexture has been used to identify pavement segregation (2). Segregation refers to separation of the coarse and fine fractions of aggregate in the paving mixture. Coarse areas tend to have lower asphalt content, lower density and higher permeability. These areas tend to fail prematurely. Areas with high levels of segregation are reported to increase the life-cycle cost to the agency by as much as 50 percent (2).

Macrotexture is also believed to be related to pavement noise, particularly for dense graded mixtures. Efforts are underway to use pavement surface type as a means to reducing pavement noise and the resulting need for sound walls.

Previous work has indicated that the CT Meter can be used to determine the texture of a pavement surface (3-5). The National Center for Asphalt Technology (NCAT) Pavement Test Track offers a unique opportunity to evaluate this tool. The test track was used to compare the CT Meter to the classic measure of pavement macrotexture which is a volumetric method, typically referred to as the "sand patch" method.

\section{PURPOSE AND SCOPE}

The objective of this study was to evaluate the Circular Texture Meter (CT Meter) (ASTM E2157) (6) for conducting texture measurements of pavement surfaces. This was accomplished by comparing the results obtained using the sand patch method (ASTM E965) (7), by evaluating the repeatability of the CT Meter as compared to the sand patch procedure, and by evaluating the reproducibility of the CT Meter by comparing three CT Meters when used to test the same locations. 


\section{TEST METHODS}

\section{Circular Texture Meter (CT Meter)}

This test procedure is presented in ASTM E2157 (6). The CT Meter uses a laser to measure the profile of a circle $284 \mathrm{~mm}$ (11.2 in) in diameter or $892 \mathrm{~mm}$ (35 in) in circumference. (See Figure 1 for a picture of the CT Meter.) The profile is divided into eight segments of $111.5 \mathrm{~mm}$ (4.4 in). The average mean profile depth (MPD) is determined for each of the segments of the circle. The reported MPD is the average of all eight segment depths.

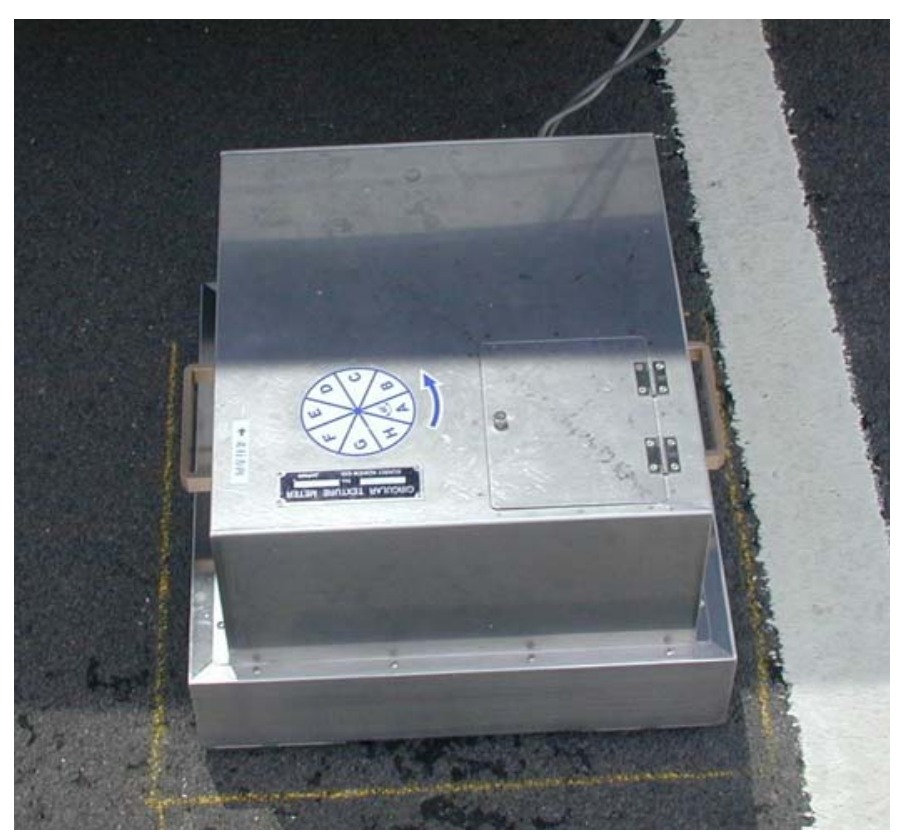

Figure 1: CT Meter.

\section{Sand Patch Method}

The test procedure used for this study follows the procedures contained in ASTM E965(7). It uses a volumetric approach of measuring pavement macrotexture. In this study a known volume of glass beads was spread evenly over the pavement surface to form a circle, thus filling the surface voids with glass beads (Figure 2). The diameter of the circle was measured on four axes and the value averaged. This value was used to calculate the mean texture depth (MTD). 


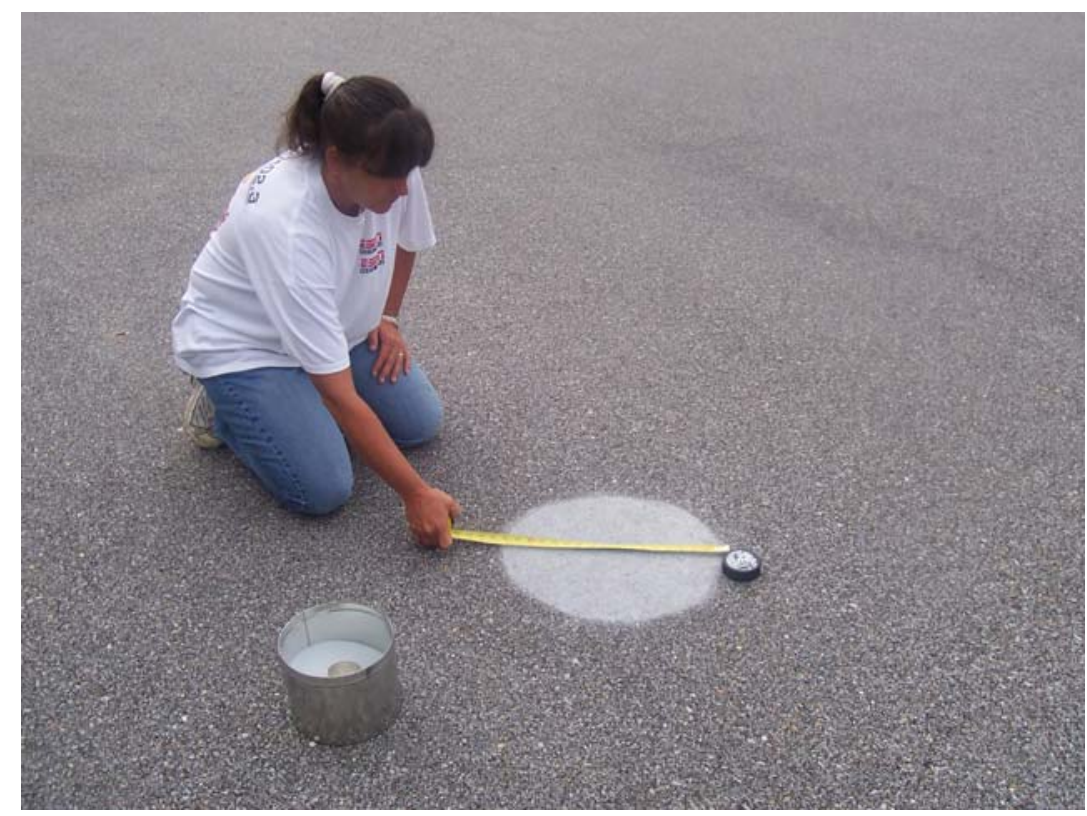

Figure 2: Sand Patch Test.

\section{NCAT TEST TRACK}

The study was conducted using an experimental asphalt pavement test track constructed in Opelika, Alabama (near Auburn University) in 2000. The test track is a $2.7 \mathrm{~km}$ (1.7 mile) oval track consisting of 46 different flexible pavement sections (26 in tangents and 20 in curves). Each test section is approximately $61 \mathrm{~m}$ (200 feet) in length.

A range of aggregate types, nominal maximum aggregate sizes (NMS), and gradations were used in the experimental sections. Two nominal maximum aggregate sizes (NMAS) are present on the track surface: $9.5 \mathrm{~mm}$ and $12.5 \mathrm{~mm}$. Gradations include fine and coarse dense graded mixtures (Superpave and Hveem), stone mastic asphalt (SMA) and open graded friction courses (OGFC). Novachip was also installed on one section to correct friction problems. Eight major aggregate types were used on the track including granites, limestone, various gravels, slag and combinations thereof including reclaimed asphalt pavement. Many of the aggregate types were represented by more than one source. Additional information on the 2000 NCAT Test Track can be found in NCAT Report 01-01 (8) and in NCAT Report 02-12 (9).

\section{RESULTS AND DISCUSSION}

\section{Relationship between CT Meter and Sand Patch Test Results}

After the completion of trafficking of the 2000 NCAT Test Track, CT Meter (ASTM E 2157) (6) and Sand Patch tests (ASTM E 965) (7) were taken at five random locations within 45 of the 46 test sections at the track (Section W10 was not tested because of its short length). The pavement was approximately 28 months old at the time the measurements were taken. Glass beads were used for the Sand Patch measurements. The CT Meter readings were taken prior 
to the Sand Patch tests so that residual sand would not affect the readings. A comparison of the CT Meter and Sand Patch results are shown in Figure 3. Each point in Figure 3 represents the average of five tests by each method. Four sections were considered to be outliers: W3, W4, W5, and W7. Sections W3, W4 and W5 were open graded friction courses (OGFC) and section W7 was a Novachip section. These types of mixes are so porous that they allow the glass beads used in the sand patch test to flow into the voids interconnected with the surface texture, producing an erroneously high result. The correlation coefficient $\left(\mathrm{R}^{2}=0.95\right)$, excluding these outliers, indicates a strong relationship between the MPD measured by the CT Meter and the MTD determined from the sand patch test. Previous work by Abe et al (3) suggested the following relationship between the CT Meter and the sand patch test:

$$
M T D=1.03 \times M P D+0.15
$$

where MTD and MPD are in mm. By comparison, the relationship produced from the NCAT Test Track data (Equation 2) indicates a negligible slope and offset. Analysis of variance (ANOVA) performed as part of the regression suggests that the offset is not significant.

$$
M T D=1.0094 \times M P D-0.0056
$$

where MTD and MPD are in mm.

\section{NCAT Test Track}

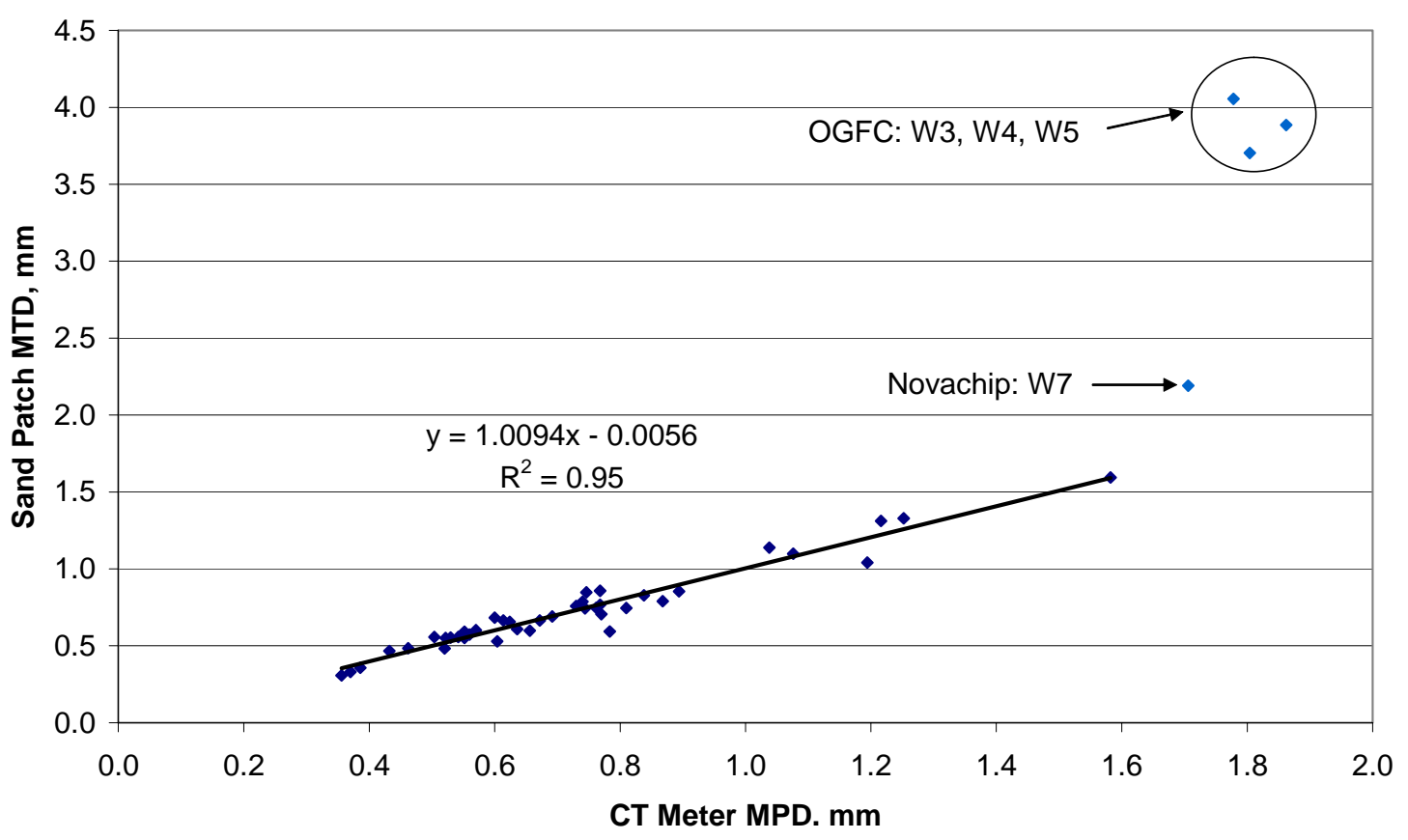

Figure 3: Relationship between CT Meter MPD and Sand Patch MTD from 2000 NCAT Test Track. 
Additional testing was conducted as part of a round robin in December 2003 at the test track. CT Meter and Sand Patch tests were conducted at ten random locations in each of six sections: S1, S2, S4, S10, S12 and W4. The sections were picked to produce a range of surface textures. Sections S1 and S4 had been repaved in the summer of 2003. Figure 4 shows a comparison between the MPD from the CT Meter and MTD from the Sand Patch tests. The relationship from Figure 3 is shown for comparison. Section W4 does not appear to be an outlier in the second round of testing. This may be because debris had previously filled or "clogged" the surface voids. The relationship between MPD and MTD for the second round of testing is slightly different than that shown in Figure 5 and heavily influenced by the results for section W4. The ANOVA performed as part of the regression analysis again indicated that the offset was again not significant.

\section{NCAT Test Track}

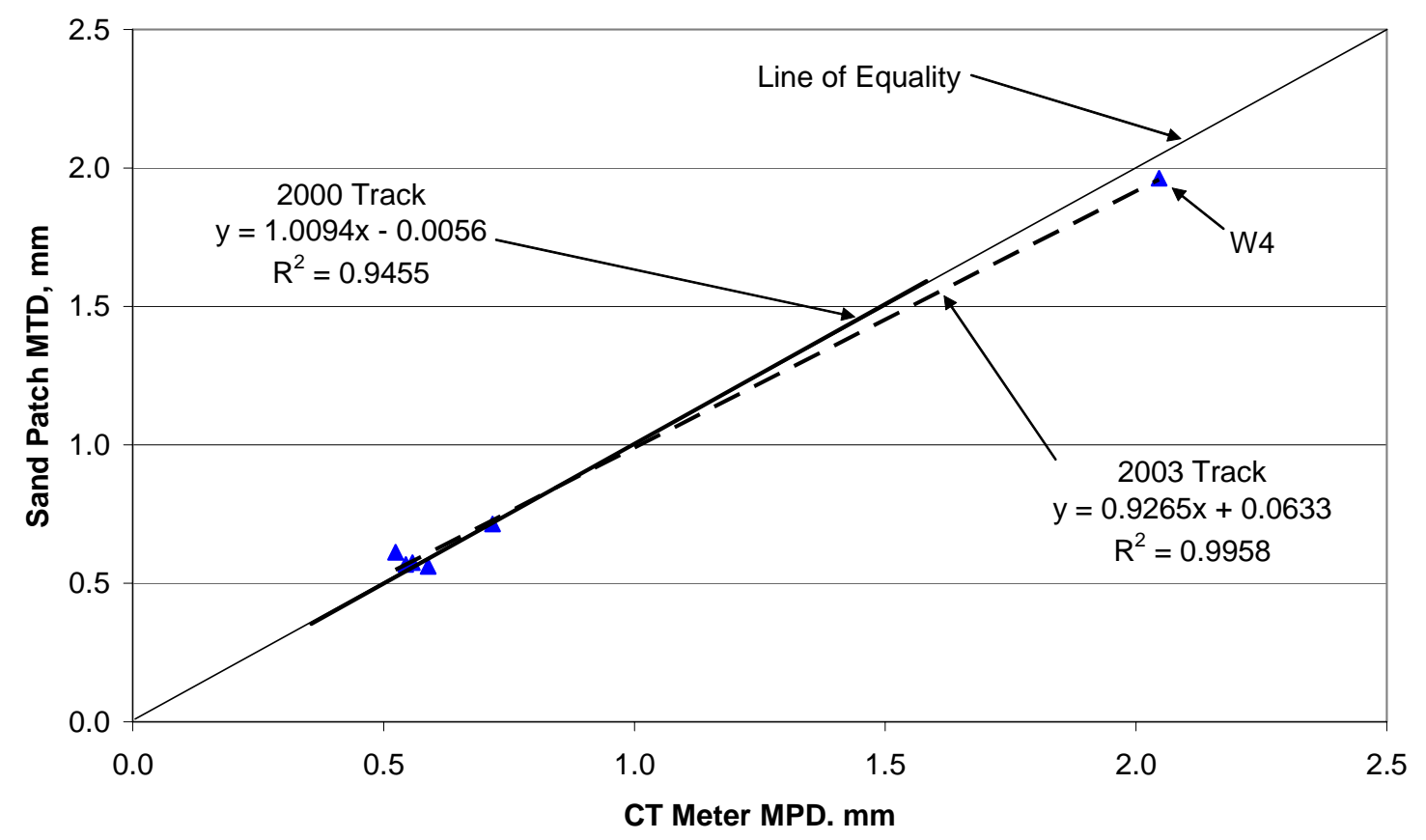

Figure 4: Relationship between CT Meter MPD and Sand Patch MTD from the NCAT Test Track

\section{Prediction of Mean Profile Depth}

NCHRP Report 441 (2) evaluated methods of quantifying segregation. Two methods of quantifying segregation were recommended: infrared thermography and dynamic texture measurements. Infrared thermography measurements need to be conducted while the hotmix asphalt (HMA) is being laid. High-speed (laser-based) texture measurements could be used to identify segregation after the HMA is laid and therefore may be more suitable for quality assurance measurements by an agency. During NCHRP 441, MPD texture measurements were made using the Road Surface Analyzer (ROSAN) system developed by FHWA (10). However, several laser based devices can produce MPD measurements 
including the CT Meter. In order to use MPD measurements to detect segregation, the "nonsegregated" texture for the mixture must be determined. The non-segregated texture could be determined by taking texture measurements in non-segregated areas or calculated based on mixture properties. Basing the non-segregated texture on actual measurements at the site adds an element of subjectivity, which such measurements are trying to avoid. Though it would be desirable to identify a "baseline" texture level directly from high-speed texture data, in practice this has been difficult (11). The prediction of HMA surface texture from laboratory properties may also be useful in evaluating a potential mixes skid and noise properties.

In the work for NCHRP 441 (2) Equation 3 was developed to predict the estimated texture depth (ETD). The sign of the coefficient for $\mathrm{C}_{\mathrm{u}}$ was corrected based on a typographical error in the NCHRP Report reported by McGhee et al (4). The estimated texture depth is an estimate of the mean texture depth (result from sand patch test) calculated using a linear transformation of the MPD, such as Equations 1 or 2 . This model was reported to have an $\mathrm{R}^{2}$ $=0.65(2)$.

$$
E T D=0.01980 \times M A S-0.004984 \times P 4.75+0.1038 \times C_{c}+0.004861 \times C_{u}
$$

where

$$
\begin{aligned}
& \text { ETD = estimated mean texture depth }(\mathrm{mm}), \\
& \text { MAS = maximum aggregate size of the mixture }(\mathrm{mm}), \\
& \text { P4.75 = percentage passing the } 4.75 \mathrm{~mm} \text { sieve } \\
& C_{c}=\text { coefficient of curvature }=\left(D_{30}\right)^{2} /\left(\mathrm{D}_{10} \times \mathrm{D}_{60}\right) \\
& C_{\mathrm{u}}=\text { coefficient of uniformity }=\mathrm{D}_{60} / \mathrm{D}_{10} \\
& D_{10}=\text { the sieve size associated with } 10 \text { percent passing }(\mathrm{mm}), \\
& D_{30}=\text { the sieve size associated with } 30 \text { percent passing }(\mathrm{mm}), \\
& D_{60}=\text { the sieve size associated with } 60 \text { percent passing }(\mathrm{mm}) .
\end{aligned}
$$

Flintsch et al. (5) reported a second equation (Equation 4) to predict the estimated texture depth based on data collected at the Virginia Smart Road. Equation 4 was developed using data collected from a system developed by International Cybernetics Corporation (ICC). This system uses a slower sensor and a larger "footprint" than the ROSAN or CT Meter systems. This model was reported to have an $\mathrm{R}^{2}=0.97$ and a root mean squared error of $0.123 \mathrm{~mm}(9)$.

$$
\text { ICCTEX }=-2.896+0.2993 \times N M A S+0.0698 \times V M A
$$

where

ICCTEX = ICC estimated texture/profile depth (mm), NMAS = nominal maximum aggregate size $(\mathrm{mm})$, VMA = voids in mineral aggregate (\%). 
McGhee et al. (4) reported that neither of these equations worked well for large stone or coarse gradation mixes. Figures 5a shows the relationship between the Sand Patch MTD measurements at the NCAT Test Track and the ETD from Equation 3. Equation 3 appears to produce outliers when the percent passing the $0.075 \mathrm{~mm}$ sieve exceeds 10 percent. In such cases, the $\mathrm{D}_{10}$ size was linearly predicted using the percentages passing the 0.150 and 0.075 $\mathrm{mm}$ sieves. This prediction does not, most likely, represent the actual $\mathrm{D}_{10}$ size. However, the actual $\mathrm{D}_{10}$ size could not be determined for mixes with greater than 10 percent passing the $0.075 \mathrm{~mm}$ sieve unless additional non-standard sieves or laser particle size analysis measurements were performed on the fines. The predictions are more reasonable for OGFC mixes (having low percentages passing the $0.075 \mathrm{~mm}$ sieve). As noted previously, the Sand Patch test tends to overestimate texture for OGFC mixtures as compared to laser-based methods such as the CT Meter.

No SMA or OGFC mixes were evaluated in the development of Equation 3. Figure 5b shows the comparison between the predicted ETD results from Equation 3 (2) and the MPD results from the CT Meter for the dense graded (Superpave and Hveem) mixtures at the NCAT Test Track. There is still a great deal of scatter in the data $\left(\mathrm{R}^{2}=0.22\right)$. However, the model was developed based on measurements taken during or soon after construction whereas the texture data from the NCAT Test Track was collected after two years of exposure to the environment. When the texture measurements were taken on the 2000 NCAT Test Track, the texture had increased since construction due to slight raveling.

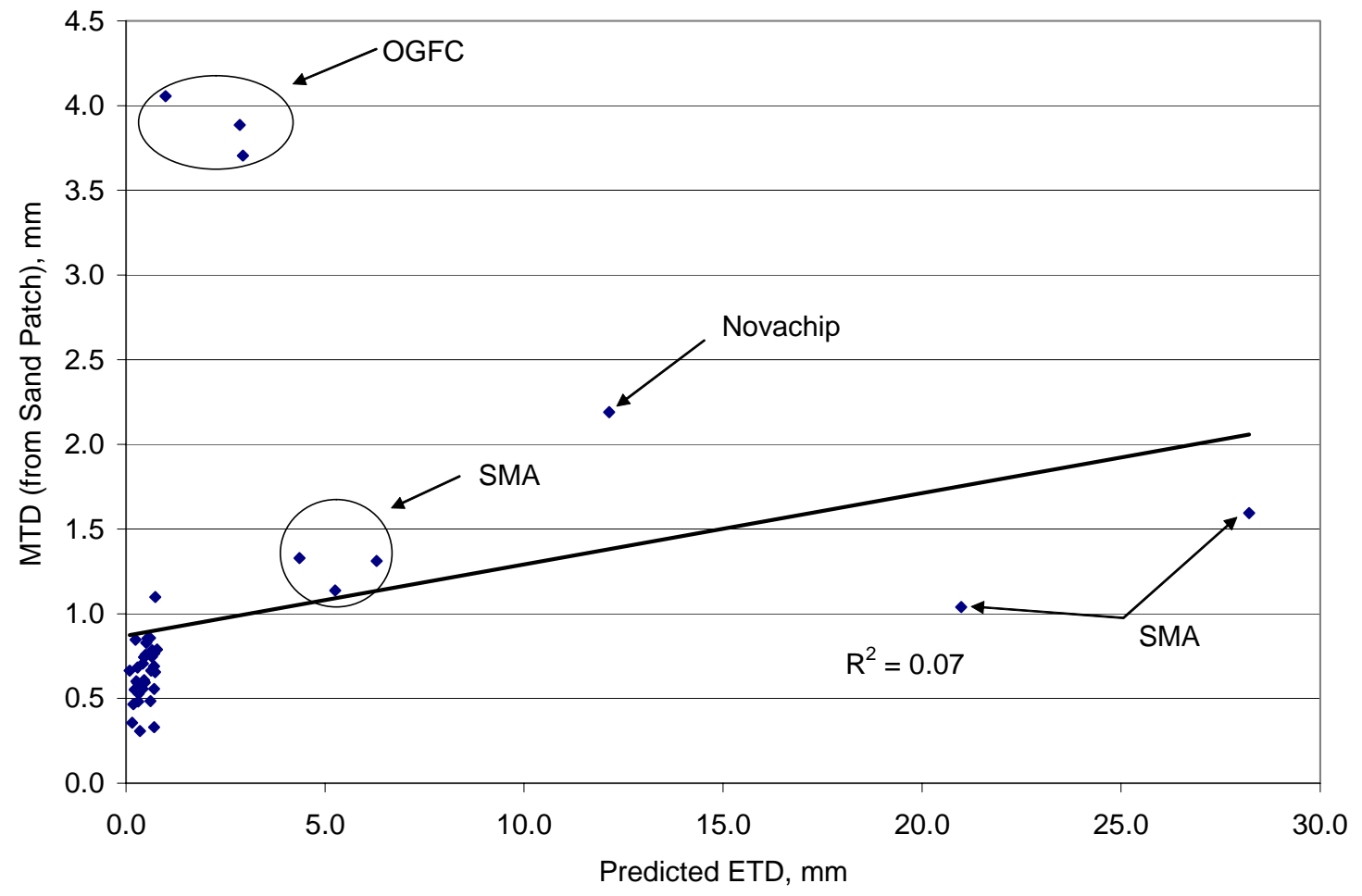

Figure 5a: Comparison of ETD from Equation 3 (2) and MTD from Sand Patch Test 


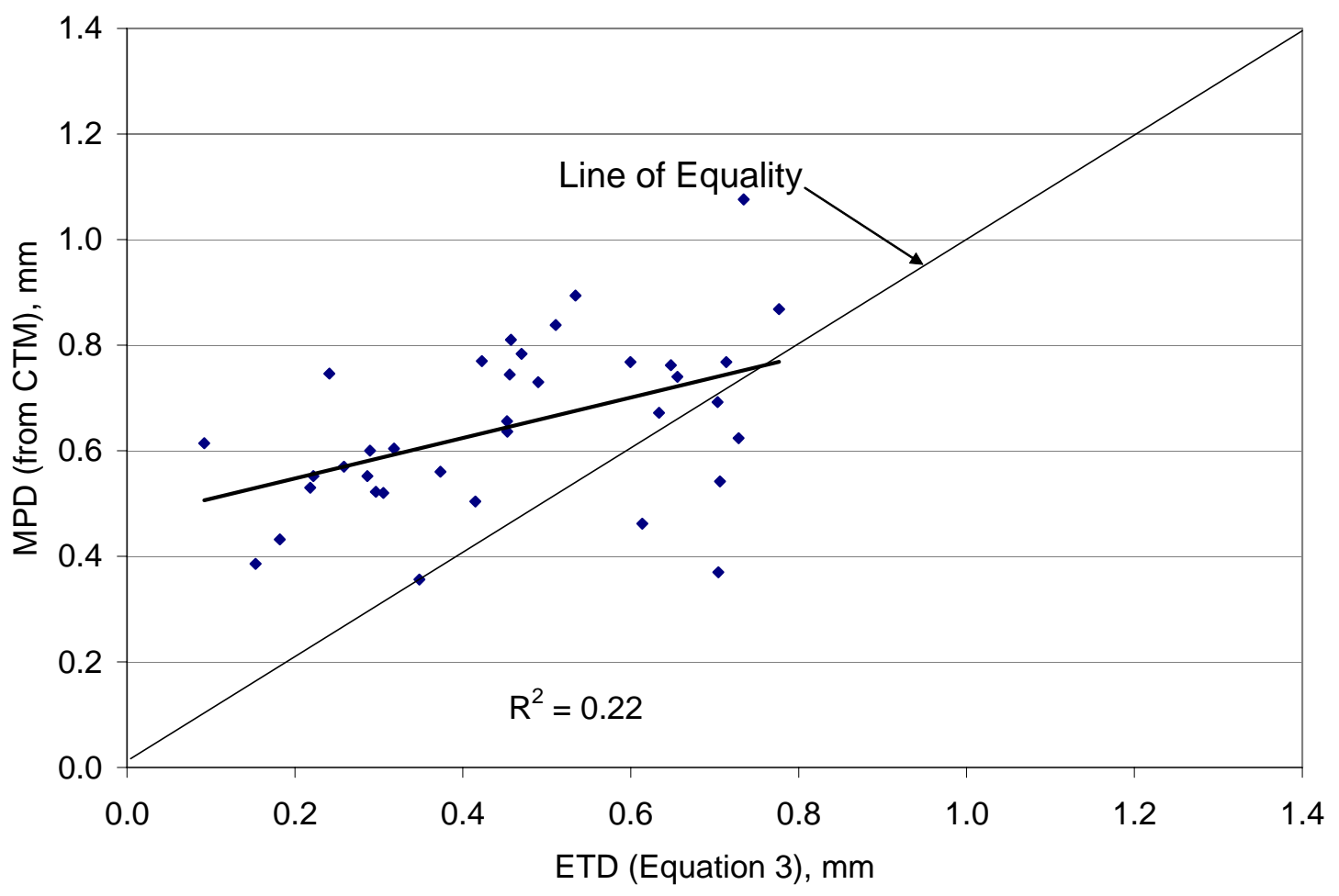

Figure 5b: Comparison of ETD from Equation 3 (2) and MPD from CT Meter for Dense Graded Mixtures

Figure 6 shows a comparison between the ICCTEX from Equation 4 and the MPD from the CT Meter. Figure 6 indicates a clear separation in the predicted texture for $9.5 \mathrm{~mm}$ and 12.5 mm NMAS mixes. This separation is not supported by the CT Meter data. Equation 5 was developed using data from the Virginia Smart Road (12). The Virginia Smart Road consists of seven different surface mixes (over 12 sections) including an SMA and OGFC section all produced using the same coarse aggregate source. It does not appear that this model is valid for a wide range of aggregate types.

An effort was made to develop an equation to predict the average texture of the Test Track data from gradation parameters and volumetric properties obtained from the quality assurance data from the Test Track construction. The test track offered a wider range of mixture properties than those used to develop Equations 3 and 4. Limitations of the data include the fact that all of the mixes were surface course and that the sections had been exposed to two years of environmental aging. Initial screening of variables was performed using step-wise regression analysis with Minitab statistical software. Variables considered included: maximum aggregate size, NMAS, percentages passing various sieve sizes, the parameters from Equation 3, fineness modulus and VMA. Fineness modulus is calculated by summing the cumulative percentages retained on the $0.15,0.30,0.60,1.18,2.36,4.75,9.5$, 19.0, 37.5, 75 and $150 \mathrm{~mm}$ sieves and dividing by 100 (ASTM C 125). Fineness modulus as the best single variable by step-wise regression. The second order polynomial relationship between fineness modulus and MTD from the Sand Patch test is shown in Equation 5 based on the data from the 2000 NCAT Test Track. The gradation and texture data for the 


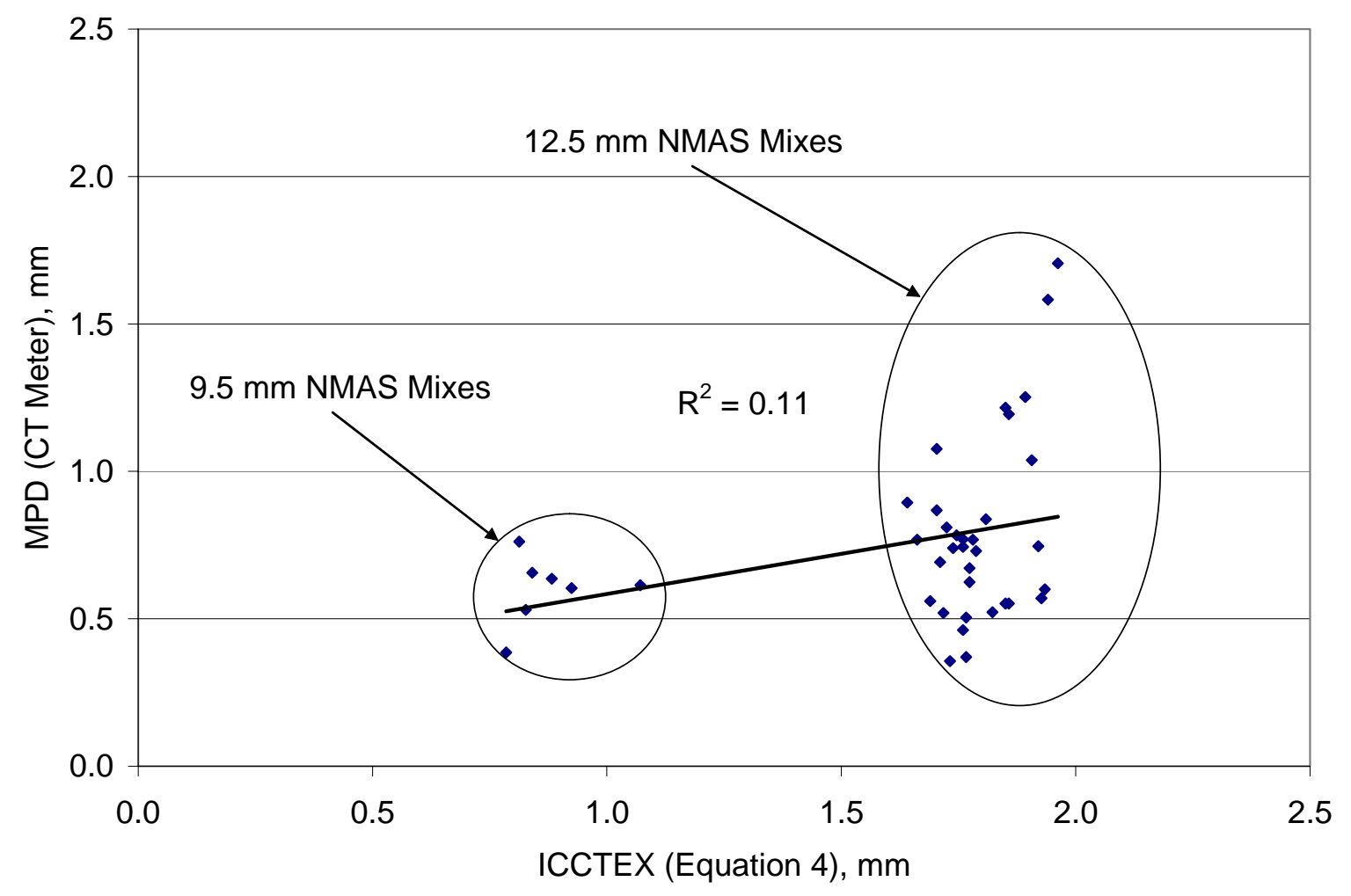

Figure 6: Comparison of ICCTEX Results from Equation 4 (5) and MPD from CT Meter

2000 NCAT Test Track are presented in Appendix A, Table A1. The data for the Novachip and OGFC sections was excluded when developing this model. The model produced an $\mathrm{R}^{2}=$ 0.62 and a root mean squared error of $0.166 \mathrm{~mm}$.

$$
M T D=0.6421 \times F M^{2}-5.235 \times F M+11.224
$$

where

MTD = mean texture depth or estimated texture depth (mm),

$\mathrm{FM}=$ fineness modulus

A similar relationship was developed between fineness modulus and the MPD from the CT Meter (Equation 6) Based on the Data from the 2000 NCAT Test Track. This model included the Novachip and OGFC sections. The model produced an $\mathrm{R}^{2}=0.84$ with a root mean squared error of $0.160 \mathrm{~mm}$.

$$
M P D=0.4973 \times F M^{2}-3.926 \times F M+8.287
$$

where

$$
\text { MPD = mean profile depth }(\mathrm{mm}) \text {, }
$$

$\mathrm{FM}=$ fineness modulus. 
One draw back to Equations 5 and 6 is that the texture data used to develop the model was measured after two years of in-service aging. Therefore similar CT Meter texture data was collected from the replacement sections of the 2003 NCAT Test Track (Appendix B, Table $\mathrm{B}-1)$. Equation 7 produced an $\mathrm{R}^{2}=0.93$ with a root mean squared error of $0.136 \mathrm{~mm}$.

$$
M P D=0.2421 \times F M^{2}-1.576 \times F M+2.727
$$

where

$$
\begin{aligned}
& \text { MPD = mean profile depth }(\mathrm{mm}), \\
& \text { FM = fineness modulus. }
\end{aligned}
$$

The relationships between the predicted and measured textures for both data sets are shown in Figure 7. Figure 7 indicates an offset between the 2000 and 2003 data. This offset is approximately $0.18 \mathrm{~mm}$. It is expected that the texture depth increased with aging due to minor loss of fines. Also, the surface course of the structural sections placed on the 2003 NCAT Test Track have lower texture values than those observed on the 2000 track (average MPD $0.14 \mathrm{~mm}$ lower).

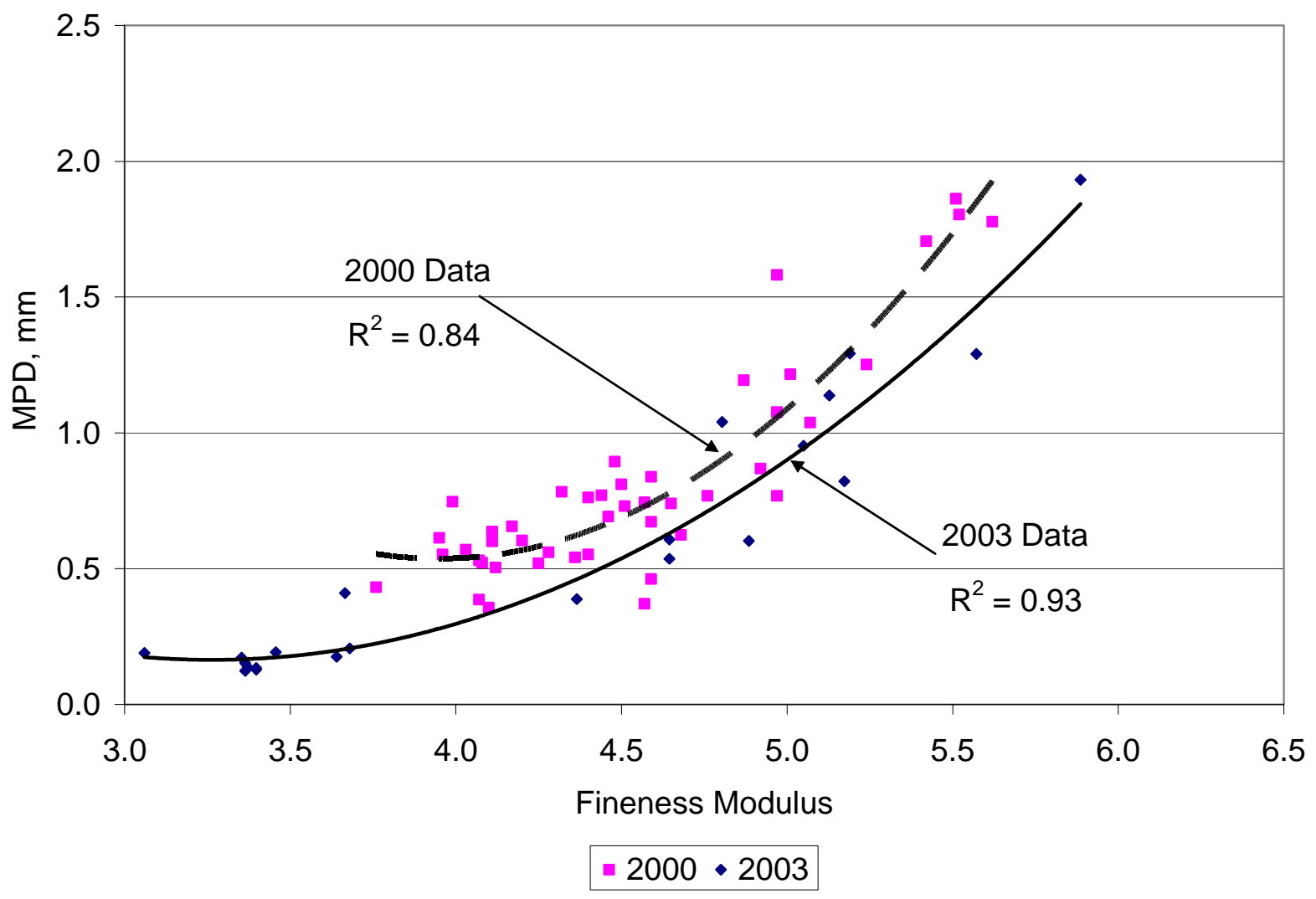

Figure 7: Comparison of NCAT Fineness Modulus Models and Test Track MPD Results for 2000 and 2003 
When developing a new model, it is always good to validate the model with independent data. To this end, Virginia Transportation Research Council was contacted to obtain gradation and texture data from the study by McGhee et al (4). VTRC's data included eight Superpave mixtures, two each of $9.5 \mathrm{~mm}, 12.5 \mathrm{~mm} 19.0 \mathrm{~mm}$ and $25.0 \mathrm{~mm}$ NMAS mixes. The study conducted by McGhee et al attempted to identify segregation using the CT Meter. For each project, texture measurements and cores were taken at five locations both within and between the wheelpath. The data used for the validation was taken from non-segregated areas between the wheelpath. Figure 8 shows the comparison between the predicted texture based on fineness modulus and the texture measured by VTRC with the CT Meter. The models appear to agree with VTRC’s data.

\section{VTRC Data}

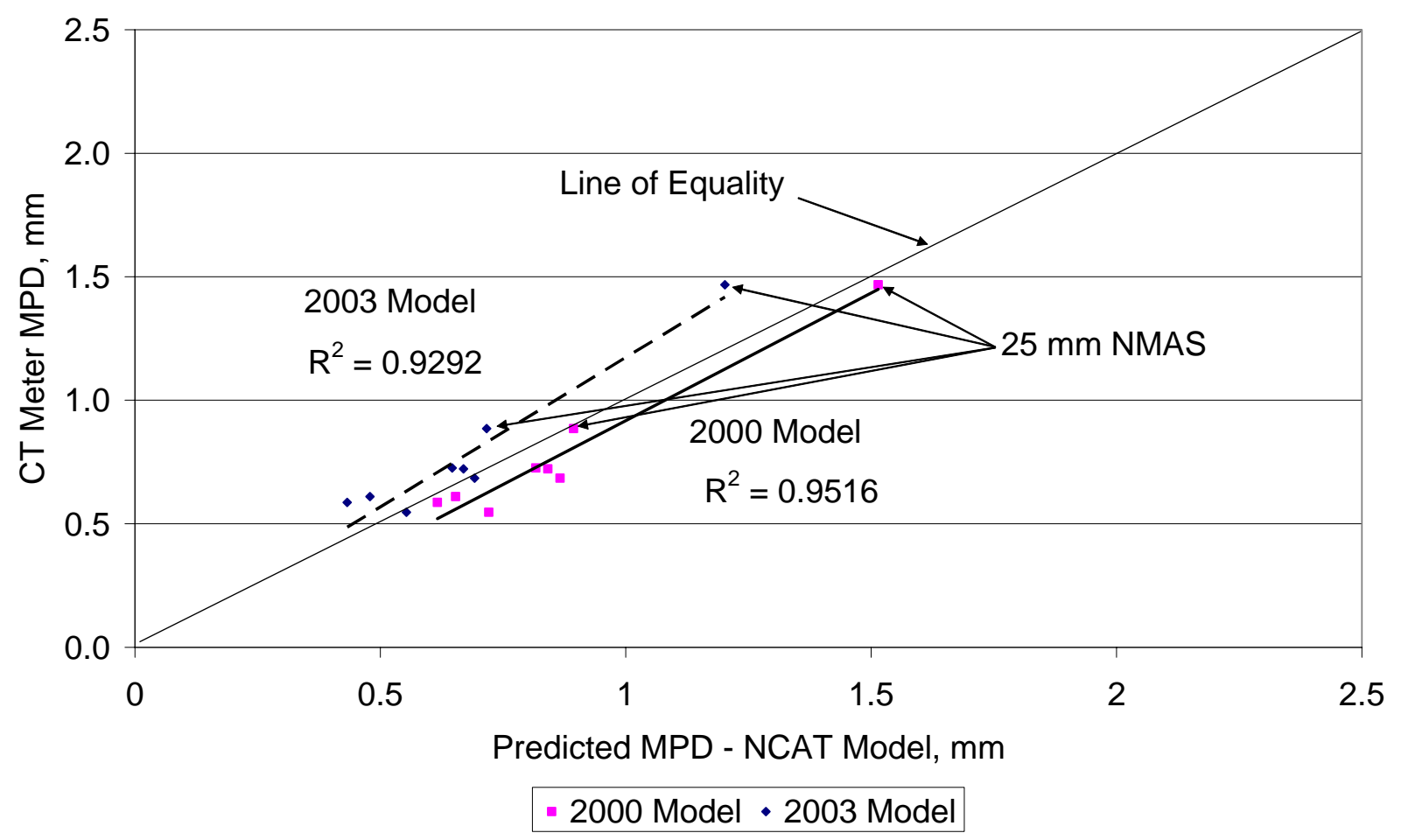

Figure 8: Comparison of Predicted Texture from Fineness Modulus Models with VTRC CT Meter Texture Data (13)

\section{Variability of CT Meter Results}

In the fall of 2003, a mini round robin was conducted at the NCAT Test Track to evaluate the variability of the CT Meter. Three agencies provided CT Meters and participated in the study: Arizona Department of Transportation, Koch Materials Company and NCAT. Three sections were selected for testing: N2, N12 and S4. N2 is a 9.5 mm NMAS fine graded Superpave mixture produced with a blend of granite and limestone. N12 is a $12.5 \mathrm{~mm}$ NMAS SMA produced with granite aggregate. S4 is a $12.5 \mathrm{~mm}$ NMAS OGFC produced with limestone aggregate. Both N2 and S4 were reconstructed in 2003. 
Ten random locations were determined for each section. All readings were taken at the same transverse location in the lane to minimize material variability. The testing order for the three machines was randomly selected for each section. The random testing order determined for each section was then used for all ten sites in that section. Triplicate readings were taken at each site.

ASTM E 691 software (14) was used to determine the precision of the CT Meter from the round robin results. Precision of the test method has two components, repeatability and reproducibility. Repeatability ( $\mathrm{Sr}$ ) is the single-operator standard deviation of the test results. Reproducibility (SR) is the multi-operator standard deviation of the test results.

The repeatability and reproducibility were calculated based on a single run, the average of two runs and the average of three runs. As expected, the repeatability and reproducibility improve by averaging multiple runs. Since the test is so fast, this does not pose a problem during field tests. Plots of the repeatability and reproducibility are shown in Figures 9 and 10, respectively. Based on Figure 9 and 10, it appears that there is a significant improvement in repeatability and reproducibility when two CT Meter runs are averaged, but little improvement resulting from averaging three runs. It is recommended that two CT Meter readings be averaged for a given site in future testing.

\section{Repeatability}

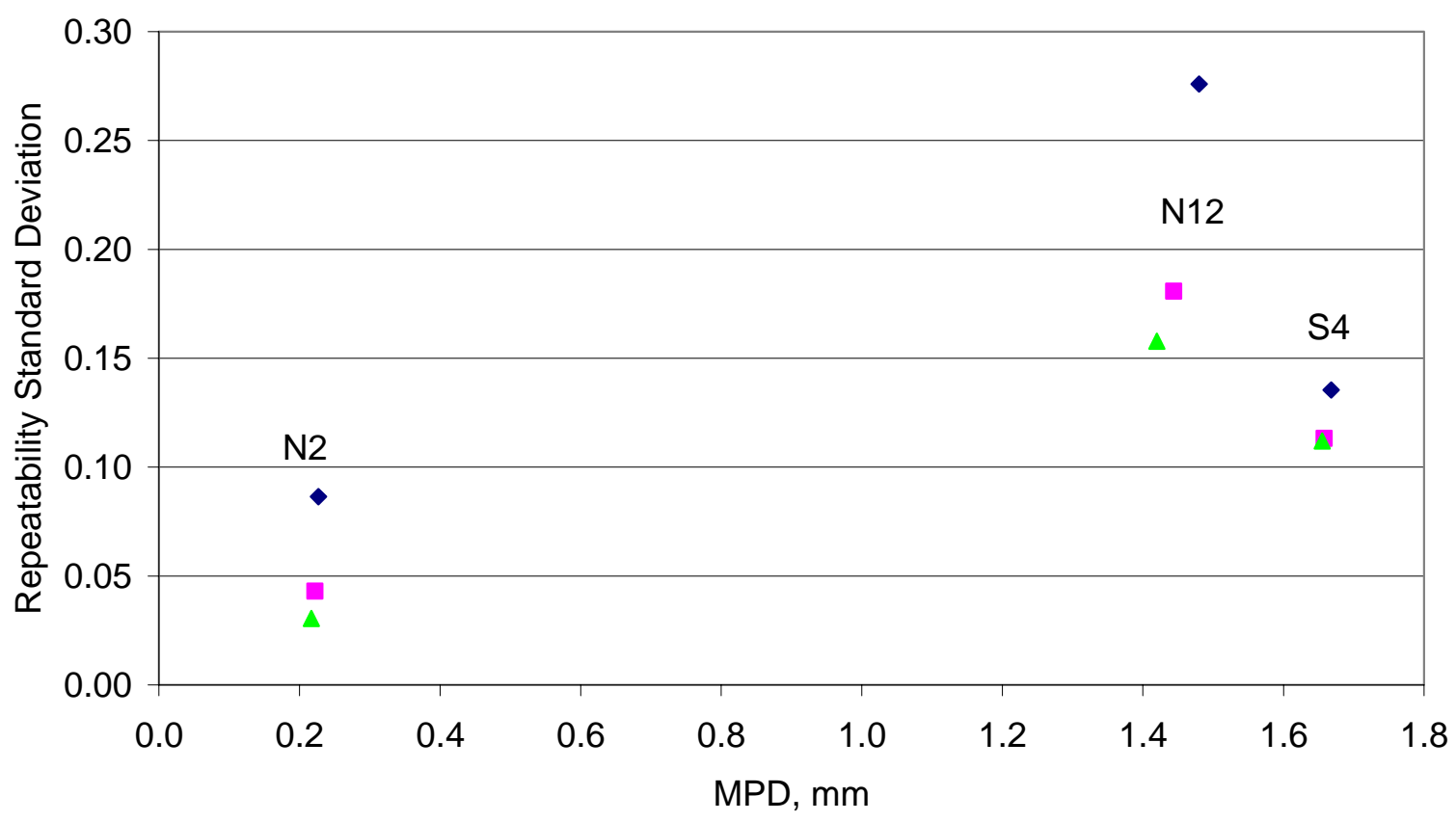

- 1 Run Avg. 2 Runs $\triangle$ Avg. 3 Runs

Figure 9: CT Meter Multi-Run Repeatability Results 
Reproducibility

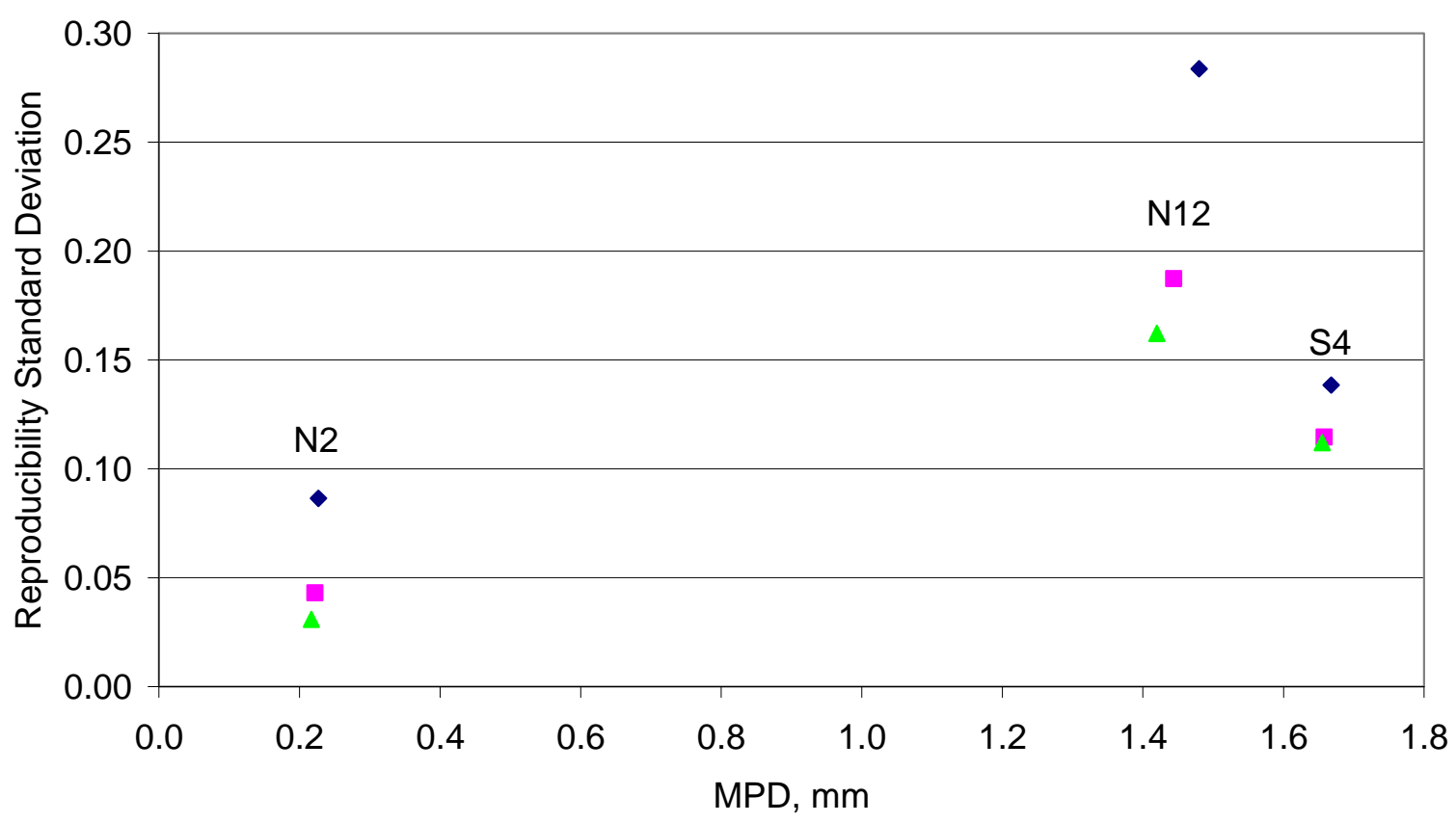

- 1 Run $\square$ Avg. 2 Runs $\triangle$ Avg. 3 Runs

Figure 10: CT Meter Multi-Run Reproducibility Results.

An Analysis of variance was performed using the general linear model using the CT Meter MPD as the response and unit, section and site (within the section) as factors (Table 1). Both section and site were significant at the 95 percent confidence level. Different textures from the different sections is expected. The fact that site was significant indicates site-to-site materials variability between the ten sites in a given section. ASTM E965 (7) notes that the coefficient of variation for site-to-site measurements within the same section may be as large as 27 percent. Since the purpose of a round robin is to determine the variability of the test method, the data was reanalyzed using the ASTM E 691 software (14) treating each site within a section as a different material. In order to have replicates, two readings could not be averaged to produce a test result.

Table 1: Analysis of Variance of Mini-Round Robin Data

\begin{tabular}{|l|c|c|c|c|c|}
\hline \multicolumn{1}{|c|}{ Source } & $\begin{array}{c}\text { Degrees of } \\
\text { Freedom }\end{array}$ & $\begin{array}{c}\text { Sum of } \\
\text { Squares }\end{array}$ & F-value & p-value & Significant? $^{1}$ \\
\hline Section & 9 & 35.72 & 1584.1 & 0.000 & Yes \\
\hline Unit & 2 & 0.01 & 0.5 & 0.603 & No \\
\hline Site & 2 & 0.27 & 2.6 & 0.010 & Yes \\
\cline { 1 - 3 } Error & 76 & 0.86 & \multicolumn{2}{|c}{} \\
\cline { 1 - 3 } Total & 89 & 36.86 & &
\end{tabular}

${ }^{1}$ Significant at the 95 percent confidence level 
ASTM E 691 (14) uses two statistics to analyze the data for consistency: $h$ and $k$. The $h$ statistic is an indicator of how one laboratory's average for a material compares with the average of the other laboratories. The $h$ statistic is based on Student's $t$ test. The $k$ statistic is an indicator of how one laboratory's variability for a given set of replicate samples compares with that of all the other laboratories. The $k$ statistic is based on the $F$ ratio. Ten $k$ outliers were identified, seven in Section N12. The $k$ outliers were removed from the data set and the precision statistics recalculated. The precision data (without outliers) is summarized in Table 2.

Table 2: CT Meter Precision Data

\begin{tabular}{lrrrrr} 
Section & Average & Sr & Sr \% & \multicolumn{1}{l}{ SR } & \multicolumn{1}{l}{ SR \% } \\
N2 & 0.211 & 0.010 & 4.710 & 0.013 & 6.235 \\
N12 & 1.387 & 0.033 & 2.395 & 0.084 & 6.077 \\
S4 & 1.654 & 0.041 & 2.458 & 0.090 & 5.449 \\
\hline Pooled & & 0.028 & 3.2 & 0.063 & 5.9
\end{tabular}

ASTM E965 (7) reports the coefficient of variation can be as low as 1 and 2 percent for repeatability and reproducibility, respectively. The coefficient of variation for the CT Meter was determined to be 3.2 and 5.9 percent for repeatability and reproducibility, respectively. This indicates that the CT Meter can be more variable than the minimum reported precision for the Sand Patch test. Averaging two measurements to produce a single test result would improve the precision of the CT Meter. The coefficient of variation for the average of two test results would be estimated to be 2.3 and 4.2 percent for repeatability and reproducibility, respectively. One reason that the precision of the CT Meter may not be quite as good as the sand patch test is that the area which the CT Meter tests to determine the pavement texture is smaller than that tested in the Sand Patch test.

\section{CONCLUSIONS}

- The CT Meter produces comparable results to the ASTM E965 Sand Patch Test. When open-graded mixtures were excluded, this study indicated that the offset was non-significant between CT Meter and Sand Patch test results. The slope of the bestfit line comparing the results was statistically significant, and ranged from 0.93 to 1.01. Thus when comparing CT Meter and Sand Patch data, the CT Meter data should be multiplied by a factor of 0.93 (2003 data) or 1.01 (2000 data) to produce comparable Sand Patch MTD values.

- Previously developed equations to predict macrotexture were found to be inadequate for the wide range of mix types (Superpave, Hveem, SMA and OGFC) and aggregate types found at the NCAT Test Track.

- An equation was developed to relate fineness modulus to macrotexture. This equation was validated with independent data collected by Virginia Transportation Research Council.

- Testing conducted as part of a mini round robin indicated that two readings should be averaged to represent a single CT Meter measurement.

- The within-lab coefficient of variation for the CT Meter is estimated to be 2.3 percent. The between lab coefficient of variation for the CT Meter is estimated to be 
4.2 percent. Both estimates are based on the average of two tests being reported as a single measurement. This indicates that the CT Meter is more variable than the sand patch test. However, less technician skill is required to operate the CT Meter.

Further, the authors question the validity of the precision of the Sand Patch test over the wide range of materials tested in this study.

\section{ACKNOWLEDGEMENT}

The authors thank the Federal Highway Administration for sponsoring this project. The authors thank Kevin McGhee of the Virginia Transportation Research Council for sharing data to validate the texture prediction model and his insight. The authors thank Buzz Powell for his assistance in gathering data from the NCAT Test Track. 


\section{REFERENCES}

1. World Road Association (PIARC), "Report of the Committee on Surface Characteristics”, XVIII World Road Congress, Brussels, Belgium, 1987.

2. Stroup-Gardiner , M., and E. R. Brown, "Segregation in Hot-Mix Asphalt Pavements,” National Cooperative Highway Research Program Report No. 441, Transportation Research Board, National Research Council, Washington, D.C., 2000.

3. Abe, H., A. Tamai, J. J. Henry, and J. Wambold, “Measurement of Pavement Macrotexture with Circular Texture Meter,” In Transportation Research Record: Journal of the Transportation Research Board, No. 1764, TRB, National Research Council, Washington, D.C., 2002, pp 201-209.

4. McGhee, K. K., G. W. Flintsch, and E. de Leon Izeppi, Using High-Speed Texture Measurements to Improve Uniformity of Hot-Mix Asphalt, VTRC 03-R12, Virginia Transportation Research Council, Charlottesville, VA, 2003.

5. Flintsch, G. W., E. de Leon, K. K. McGhee, and I. L. Al-Qadi, "Pavement Surface Macrotexture Measurement and Applications,” In Transportation Research Record: Journal of the Transportation Research Board, No. 1860, TRB, National Research Council, Washington, D.C., 2003, pp 168-177.

6. Standard Test Method for Measuring Pavement Macrotexture Properties Using the Circular Track Meter, American Society for Testing and Materials, ASTM Designation E2147, Volume 04.03 Road and Paving Materials; Vehicle-Pavement Systems, 2004.

7. Standard Test Method for Measuring Pavement Macrotexture Depth Using a Volumetric Technique, American Society for Testing and Materials, ASTM Designation E965, Volume 04.03 Road and Paving Materials; Vehicle-Pavement Systems, 2004.

8. Powell, R. B., “As-Built Properties of Experimental Sections on the 2000 NCAT Pavement Test Track,” NCAT Report No. 01-02, National Center for Asphalt Technology, Auburn, AL., 2001.

9. Brown, E. R., L. A. Cooley, Jr., D. Hanson, C. Lynn, B. Powell, B. Prowell, and D. Watson, “NCAT Test Track: Design, Construction and Performance," NCAT Report No. 02-12, National Center for Asphalt Technology, Auburn, AL., 2002.

10. Federal Highway Administration. "Rosan Makes Manual Pavement Testing Obsolete.” Publication FHWA-RD-97-011. U. S. Department of Transportation, 1997.

11. Personal Communication with K. McGhee, Virginia Transportation Research Council, July 21, 2004.

12. Davis, R. M., G. W. Flintsch, I. L. Al-Qadi, and K. K. McGhee. "Effect of Wearing Surface Characteristics on Measured Pavement Skid Resistance and Texture.” CD-ROM, Presented at the Annual Meeting of the Transportation Research Board, Washington, D.C., 2002.

13. Personal Communication with K. McGhee, Virginia Transportation Research Council, July 13, 2004.

14. American Society for Testing and Materials. Interlaboratory Data Analysis Software: E 691 User's Guide. Philadelphia, 1990. 
Hanson \& Prowell

Appendix A 
TABLE A1 2000 NCAT Test Track Texture and Gradation Data

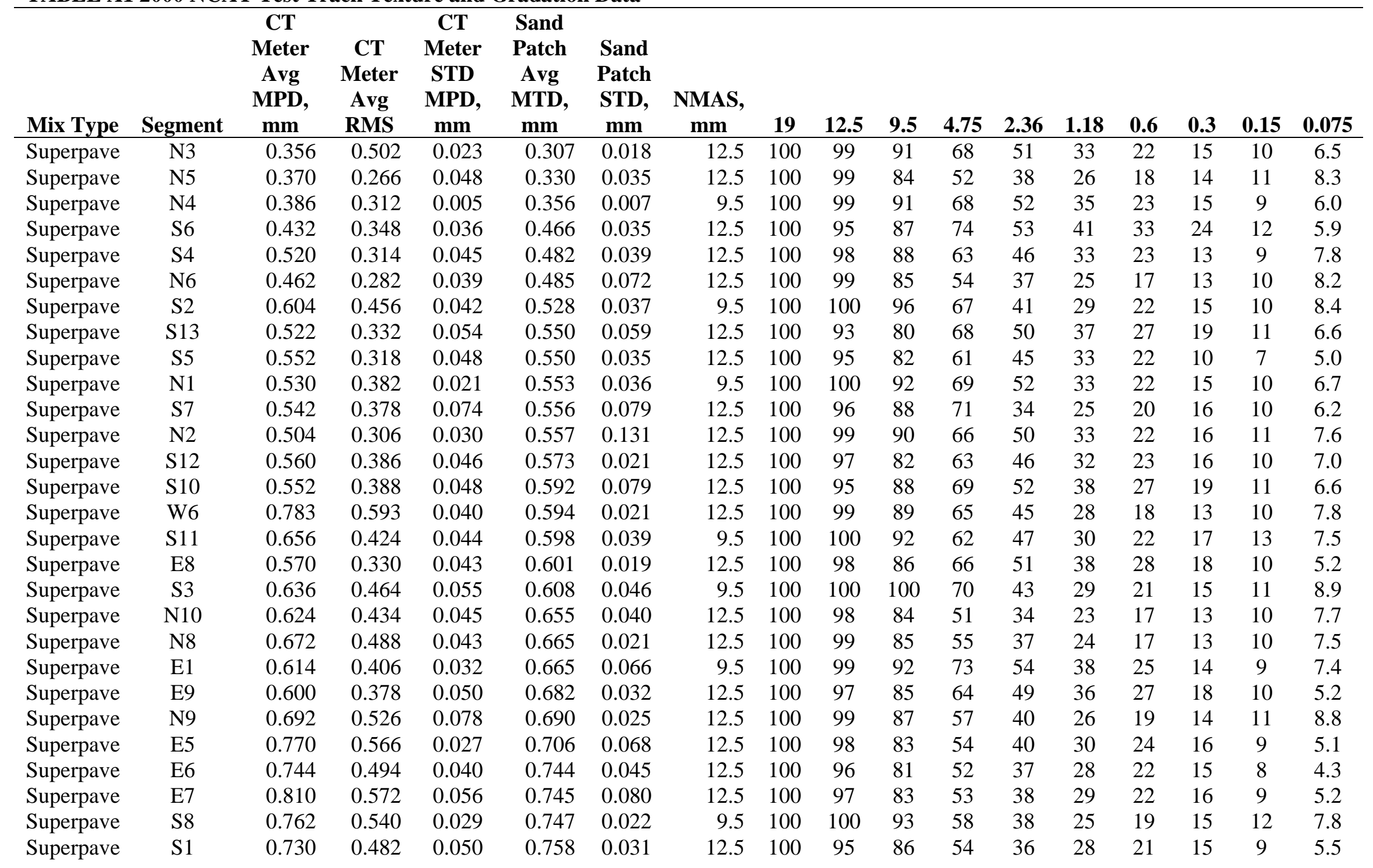


TABLE A1 2000 NCAT Test Track Texture and Gradation Data

\begin{tabular}{|c|c|c|c|c|c|c|c|c|c|c|c|c|c|c|c|c|c|}
\hline Mix Type & Segment & $\begin{array}{c}\text { CT } \\
\text { Meter } \\
\text { Avg } \\
\text { MPD, } \\
\text { mm }\end{array}$ & $\begin{array}{c}\text { CT } \\
\text { Meter } \\
\text { Avg } \\
\text { RMS }\end{array}$ & $\begin{array}{c}\text { CT } \\
\text { Meter } \\
\text { STD } \\
\text { MPD, } \\
\text { mm }\end{array}$ & $\begin{array}{c}\text { Sand } \\
\text { Patch } \\
\text { Avg } \\
\text { MTD, } \\
\text { mm }\end{array}$ & $\begin{array}{c}\text { Sand } \\
\text { Patch } \\
\text { STD, } \\
\text { mm }\end{array}$ & $\begin{array}{c}\text { NMAS, } \\
\text { mm }\end{array}$ & 19 & 12.5 & 9.5 & 4.75 & 2.36 & 1.18 & 0.6 & 0.3 & 0.15 & 0.075 \\
\hline Superpave & E2 & 0.768 & 0.614 & 0.069 & 0.767 & 0.039 & 12.5 & 100 & 96 & 74 & 41 & 29 & 22 & 18 & 12 & 7 & 4.1 \\
\hline Superpave & N7 & 0.740 & 0.542 & 0.029 & 0.786 & 0.047 & 12.5 & 100 & 98 & 83 & 52 & 36 & 24 & 17 & 13 & 10 & 7.8 \\
\hline Superpave & E4 & 0.868 & 0.660 & 0.149 & 0.789 & 0.063 & 12.5 & 100 & 95 & 75 & 42 & 29 & 23 & 18 & 13 & 8 & 4.6 \\
\hline Superpave & S9 & 0.838 & 0.570 & 0.033 & 0.828 & 0.071 & 12.5 & 100 & 93 & 82 & 53 & 36 & 27 & 20 & 14 & 9 & 5.7 \\
\hline Superpave & W9 & 0.768 & 0.628 & 0.058 & 0.857 & 0.061 & 12.5 & 100 & 96 & 80 & 51 & 34 & 22 & 16 & 12 & 9 & 6.7 \\
\hline SMA & W8 & 1.194 & 0.942 & 0.146 & 1.040 & 0.105 & 12.5 & 100 & 99 & 80 & 33 & 25 & 22 & 20 & 18 & 15 & 12.9 \\
\hline Superpave & E3 & 1.076 & 0.794 & 0.068 & 1.099 & 0.089 & 12.5 & 100 & 94 & 73 & 41 & 29 & 23 & 18 & 12 & 7 & 4.2 \\
\hline SMA & W2 & 1.038 & 0.742 & 0.057 & 1.138 & 0.096 & 12.5 & 100 & 98 & 77 & 35 & 24 & 17 & 15 & 13 & 12 & 10.7 \\
\hline SMA & N12 & 1.216 & 1.074 & 0.118 & 1.312 & 0.093 & 12.5 & 100 & 96 & 73 & 32 & 23 & 21 & 19 & 17 & 14 & 11.2 \\
\hline SMA & W1 & 1.252 & 1.092 & 0.098 & 1.328 & 0.135 & 12.5 & 100 & 95 & 68 & 28 & 20 & 18 & 16 & 14 & 12 & 9.7 \\
\hline OGFC & W3 & 1.778 & 1.436 & 0.077 & 4.055 & 0.827 & 12.5 & 100 & 98 & 68 & 19 & 13 & 11 & 10 & 9 & 8 & 6.8 \\
\hline
\end{tabular}




\section{Appendix B}


TABLE B1 2003 NCAT Test Track Texture and Gradation Data

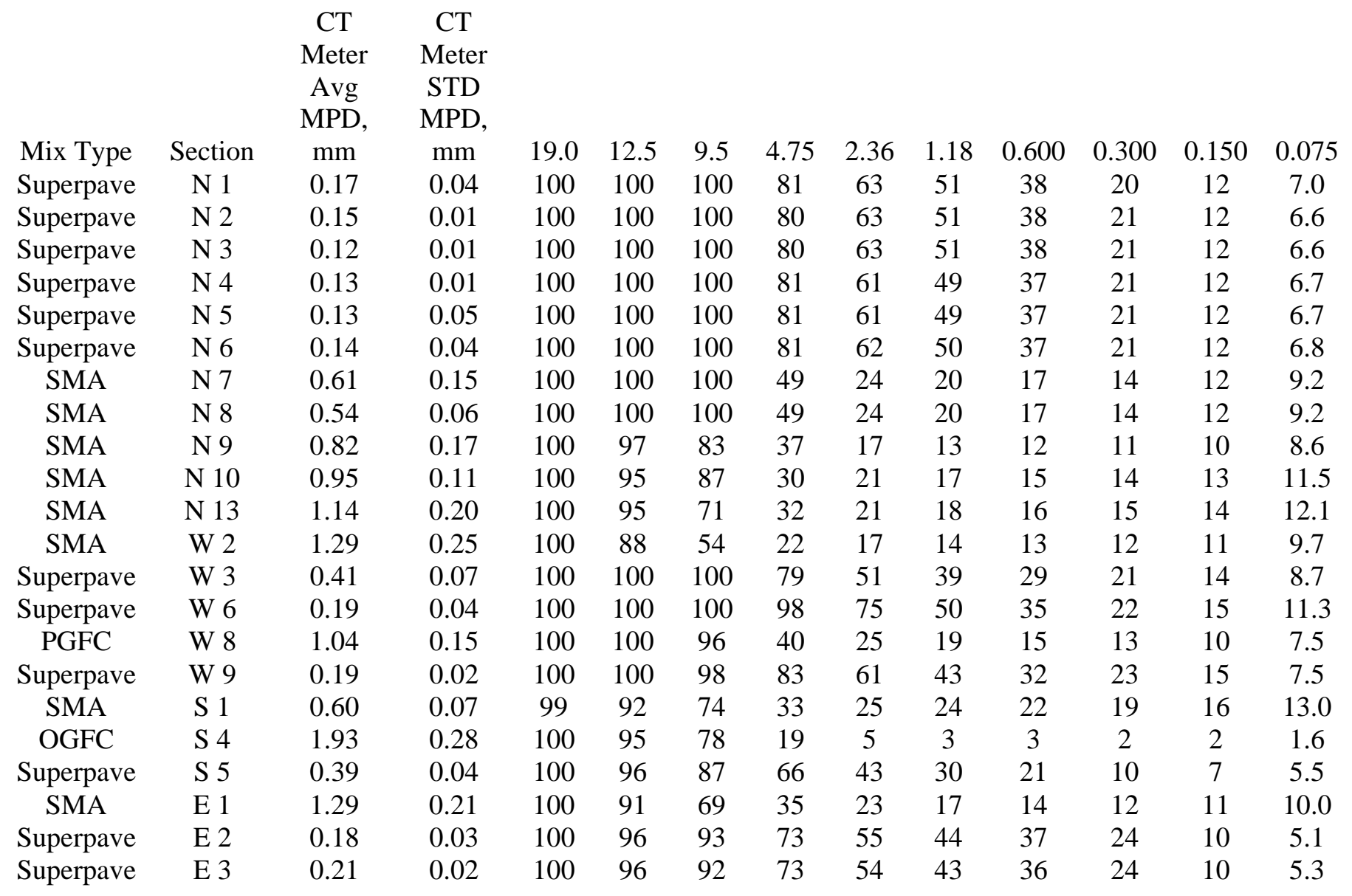

